\title{
OS DESAFIOS E PERSPECTIVAS DO ENSINO SUPERIOR NO BRASIL
}

\author{
Vicenilda David Cordeiro ${ }^{1}$ \\ Maria do Socorro Vaz da Silva ${ }^{2}$ \\ Francisco Edson do Nascimento Costa ${ }^{3}$
}

RESUMO: Este trabalho tem por finalidade discutir os desafios do ensino superior noBrasil, especificamente relativo à formação em sala de aula, percorrendo as sérias problemáticas advindas com a fragilidade do processo formativo, bem como a reflexão acerca das mudanças necessárias para seu aperfeiçoamento.

Palavras-Chave: Educação. Ensino superior. Formação. Pedagogia. Democratização. Ensino remoto.

\section{INTRODUÇÃO}

Este artigo, que faz parte da disciplina de Docência no Ensino Superior, docurso de Mestrado em Ciências da Educação, da Facem, tem por objetivo abordar desafios e fragilidades do Ensino Superior no Brasil, percebendo o atual contexto e alternativas especialmente para se repensar o magistério e o aperfeiçoamento do processo de ensino-aprendizagem, na formação de professores enquanto agentes de transformação e não meramente repassadores de conteúdo. Alguns caminhos desvelam-se para se encontrar possibilidades que serão vistas nas linhas que se seguem.

\footnotetext{
${ }^{1}$ Mestranda em Ciências da Educação pela FACEM, Polo Fortaleza, Graduada em Pedagogia pela Universidade Estadual da Educação - UECE (1997) e Licenciatura em História pela Universidade Vale do Acaraú -UVA (2007). Especialista em Metodologia do Ensino Fundamental-UECE (1999) e Gestão da Educação Pública pela Universidade Federal de Juiz de Fora (2orI). Cursando Mestrado em Ciências da Educação pela Faculdade de Administração Comércio e Empreendedorismo. Atua na educação desde 1997, como professora e gestora. Atualmente Orientadora da Célula de Desenvolvimento da Escola e da Aprendizagem (CEDEA 2) da Coordenadoria de Desenvolvimento da Educação 2- Itapipoca-CE.

2 Mestranda em Ciências da Educação pela FACEM, Polo Fortaleza, graduada em Direito pela Universidade Federal do Ceará, Funcionária Pública Federal, com exercício no IFCE.

${ }^{3}$ Mestrando em Ciências da Educação pela FACEM, Polo Fortaleza, graduado em História, pela Uece, e em Comunicação Social - Jornalismo, pela UFC, é especialista em História do Brasil, pelo INTA.
} 


\section{DESAFIOS NO ENSINO SUPERIOR}

Relacionado ao Ensino Superior alguns desafios podem ser detectados. Iniciamos nossa reflexão trazendo à tona o texto "Inovações na educação superior: experiências na América Latina”, em que o professor Juan Carlos Tedesco avalia as relações entre a expansão da Educação Superior (ES).

Segundo o autor, a heterogeneidade é uma característica marcante da ES na América Latina $(\mathrm{AL})$, inclusive no que tange à expansão. Apesar disso, de forma geral, pode-se dizer que ocorreu, em grande parte, por conta do setor privado e de IES não universitárias.

Lembra o professor Tedesco que os países da AL são iguais,principalmente, na exclusão social - todos os países têm forte dívida com diversos setores sociais. Portanto, em sua perspectiva, é preciso tratar da ES como parte de um projeto de sociedade - ou seja, se queremos construir sociedades mais justas, teremos de pensar as tendências da ES a partir daí.

Nesse sentido, destacamos três grandes categorias de problemas que afetam a Educação Superior: I. a necessidade de democratizar a universidade, do ponto de vista do acesso e da permanência; 2. o imperativo de democratizar a gestão - formas de tomar decisões com maior inclusão; e 3. a importância de democratizar conteúdos e o que faz/oferece a universidade - rever a pertinência do que produz e redistribui.

Sobre o problema do acesso e da permanência, indica a necessidade de colocar na agenda o tema da pedagogia universitária, para equacionar a questão do fracasso universitário, assumindo com plenitude o conceito de aprendizagem ao longo da vida, proposto pela UNESCO, o que significa tomar a questão do "aprender a aprender" e do "ensinar a ensinar" com seriedade, edefinir a responsabilidade da ES com a educação básica. Quanto à questão dagestão da universidade, Tedesco avalia que a autonomia universitária, que forafundamental no processo de resistências e lutas contra as ditaduras, hoje tem adquirido características de corporativismo acadêmico, exigindo uma revisão das formas de governo das Instituições de Ensino Superior (IES). Sobre os conteúdos e o que faz/oferece, a universidade traz ao debate a questão da qualidade das IES com pertinência social, para além da mercantilização. Afirma, assim, que hoje, mais do que nunca, é preciso formar inteligências responsáveis. Os grandes debates contemporâneos exigem visão social 
- poisos problemas que os geram não advêm de falhas técnicas, mas sim de falta de dimensão cidadã, de ética e de responsabilidade coletiva no uso deconhecimentos científicos, estando ausente a perspectiva de sociedade justa,igualitária e inclusiva.

De acordo com o texto estudado na disciplina de "Docência no Ensino Superior”, intitulado "Metodologia do Ensino Superior”, de Antônio Gil (1990), a preparação precária do professor universitário brasileiro constitui uma realidade. Muitos ainda pensam que basta o domínio do conteúdo para lecionar qualquer disciplina, ignorando a necessidade de um sistemático processo de formação pedagógica. Esse é um grande desafio a ser enfrentado no Ensino Superior. Além disso, os currículos ficam "amarrados", com uma infinidade dedisciplinas e cursos obrigatórios. Pode-se inferir a prioridade da quantidade, em vez da qualidade.

Outro desafio é o da qualidade, atestando-se uma massificação cada vez maior do acesso à universidade, em detrimento de uma certa fragilidade na educação básica, basilar na formação acadêmica mais consolidada.

Outro desafio é institucional. O marco legal do Ensino Superior no Brasil é baseado na ideia de uma "Universidade de Ensino, Pesquisa e Extensão", mas nem

todas as IES cumprem esses três pilares, o que cria um custo considerável para que se cumpra o modelo ou se burle a legislação. O sistemade gestão das universidades públicas, frequentemente, não oferece estímulos para que sejam eficientes. Outrossim, oferecemos pouquíssimos atrativos parabons alunos de graduação.

O Brasil tem desafios gigantescos para acertar o seu Ensino Superior. Háilhas de excelência aqui e ali, mas são ilhas nas quais as instituições, professores e pesquisadores pagam um preço alto.

Os jovens estão cada vez mais dispostos a obter uma educação no Brasilque aumente suas habilidades, ao invés de entrar no mercado de trabalho diretamente após a conclusão do ensino obrigatório. Até mesmo com o viés deconquistar melhor qualidade de trabalho e de vida; mas que tipo de formação esse profissional tem tido na Universidade?

\section{POSSIBILIDADES DE UM NOVO CAMINHO}

Ao analisar a obra de Antônio Gil, "A metodologia do Ensino Superior", a qual analisamos a fundo nesta disciplina, nos deparamos com estratégias modernas de 
ensino-aprendizagem, por meio de uma ordenação sistemática dos conteúdos a serem apresentados em sala de aula. Recursos e metodologias que, muitas vezes, encontram uma fragilidade nos cursos de ensino superior. Pelo uso limitado e muitas vezes arcaico de alguns docentes, que não motivam de fato o discente, vê-se uma fragilidade no processo formativo, o que repercute na fragilidade da qualidade do ensino.

$\mathrm{Na}$ nossa realidade, por vezes presenciamos a falta de comprometimento de alguns docentes e certo sucateamento na própria Universidade, com carência de livros e instrumentação, o que reflete na qualidade do curso. Problema este compartilhado por outros colegas da disciplina.

Mas nem tudo está perdido. Nesta disciplina, consideraram-se algumas alternativas, ensejando por um novo perfil de docentes que comunguem com a educação libertadora, a qual preconizava o educador Paulo Freire, em detrimento da educação bancária, deformadora do processo de ensino- aprendizagem.

Por mais qualidade em nossas Universidades!

\section{OS DESAFIOS DO ENSINO REMOTO NO CONTEXTO DA PANDEMIA COVID-I9}

Quando abordamos os desafios do Ensino Superior, não podemos descuidar do grande impacto na área advindo com a conjuntura da pandemia da Covid-I9 onde se atestam inúmeras adversidades. $O$ ano de 2020 foi marcado por uma gravíssima crise sanitária mundial com o surgimento do coronavírus, que se espalhou de forma muito rápida por todo mundo. Diante de tal situação foi preciso adotar medidas sanitárias no intuito de tentar contero avanço do vírus, tais como: lavagem das mãos, uso de álcool em gel, uso de máscaras, distanciamento social, fechamento de estabelecimentos diversos, dentre outros. Tais medidas foram adotadas para evitar aglomerações e tentar frear o avanço das contaminações. Conforme esclarece Charczuk (2020), escolas e universidades foram alguns dos primeiros espaços a serem fechados. Ainda de acordo com a autora, com a impossibilidade de habitar esses tradicionais estabelecimentos de ensino, vislumbrou-se o desafio de refletir sobre outros modos de estruturar os processos de ensinar, assim como deaprender, 
fora do ambiente escolar e acadêmico.

Com os estabelecimentos de ensino fechados, surgiu um grande desafio para dar prosseguimento aos processos de ensino e aprendizagem, como também ao exercício da docência. Diante da situação imposta, a estratégia encontrada foi o emprego do ensino remoto com o uso de ferramentas disponibilizadas pela internet. Com a adoção do ensino on-line surgiu mais um grande desafio para os sujeitos envolvidos no processo: professores, alunos e também as famílias. Outro fator desafiante foi causado pela forte desigualdade socioeconômica existente em nosso país. Conforme Charczuk (2020), o formato de ensino remoto ocasionou uma série de críticase resistências pelos sujeitos envolvidos e também da sociedade civil. A autora destaca como focos da problematização: a enorme desigualdade socioeconômica dos brasileiros e a falta de recursos necessários para o acompanhamento das aulas remotas.

No tocante ao exercício da docência em tempos de ensino remoto, os desafios foram muitos. Acostumados ao ambiente físico de escolas e universidades, os professores se viram diante de uma situação que exigiu que os mesmos se reinventassem e muitos não estavam preparados para lidar como ensino no formato on-line, não estavam preparados para trabalhar com novas Tecnologias Digitais da Comunicação e Informação (TIDCS). Conforme Assevera Behar (2020), foi preciso pensar em atividades pedagógicas mediadas pelo uso da internet como forma de minimizar os impactos na aprendizagem advindos do ensino presencial. O currículo da maior parte das IES que adotam a modalidade presencial não foi preparado para ser aplicado remotamente, ocasionando mudanças na forma de pensar e fazer educação.

\section{CONCLUSÃO}

Concluímos este artigo reafirmando que é plenamente possível superar os desafios do Ensino Superior. Um dos primeiros passos para isso é o professortomar consciência de sua responsabilidade e adotar técnicas eficazes para aperfeiçoamento do processo ensino-aprendizagem, a exemplo do que preconiza Antonio Gil, autor ao qual estudamos nesta disciplina. Por meio de um planejamento e métodos de discussão e avaliação eficazes, há que se dispor de um grande diferencial formativo 
nos bancos acadêmicos, para que possa ocorrer uma mudança no processo de formação dos profissionais do ensino superior, com possibilidades de foco na ética e no comprometimento dos processos de ensino e na aprendizagem dos discentes.

Esse grau de consciência também deve partir de nós, acadêmicos de Mestrado na área de Educação, ao refletirmos as fragilidades e novas possibilidades. Daí a importância de abordarmos pontos assim para aperfeiçoar modelos mais eficazes de docência e mais qualidade no ensino superior.

Outra questão é a necessidade de potencializar a democratização da gestão e do acesso ao Ensino Superior, com vistas ao progresso educacionale social.

\section{REFERÊNCIAS BIBLIOGRÁFICAS}

GIL, Antonio Carlos. Metodologia do Ensino Superior. São Paulo: Ed. Atlas, S.A., 1990

SPELLER, Paulo. Experiências recentes de inovação na Educação superior - o contexto internacional. DESAFIOS E PERSPECTIVAS DA EDUCAÇÃO SUPERIOR BRASILEIRA PARA A PRÓXIMA DÉCADA. Brasília : UNESCO, CNE, MEC, 2012.

CHARCZUK, Simone Bicca. Sustentar a Transferência no Ensino Remoto: Docência em tempo de pandemia, 2020. Disponível em https://www.scielo.br/j/edreal/a/S7dGKjBx7Ch4FxCwVc93pVg/?lang=pt. Acesso em: 27 ago. 2021.

BEHAR, Patrícia Alejandra. O Ensino Remoto Emergencial e a Educação a Distância, 2020. Disponível em https://www.ufrgs.br/coronavirus/base/artigo- oensino-remoto-emergencial-e-a-educacao-a-distancia/. 